\title{
Digital Music Libraries: Librarian Perspectives and the Challenges Ahead
}

\section{by Meghan Goodchild}

\section{Abstract}

This paper reports the results of a survey targeting current members of the Canadian Association of Music Libraries, Archives and Documentation Centres (CAML) that investigated the extent to which the current designs and structures of digital music libraries meet the needs of librarians in collecting, preserving, organizing, and disseminating diverse types of music documents. The challenges and barriers experienced in hosting digital collections are discussed. The gap between the current and ideal functionalities, as well as the future possibilities, are explored.

Keywords: digital music library, librarian, Canada, survey, digital collection, music information retrieval

\section{Introduction}

There has been growing interest in the digital music library, ${ }^{1}$ which can be defined as "a focused collection of digital objects-including text, audio and video-along with methods for access and retrieval, and for selection, organisation, and maintenance." ${ }^{2}$ In an article published a decade ago, Dunn et al. predicted the future of digital music libraries, imagining that a graduate student in ten years would be able to exploit functionalities such as synchronizing several recordings to a symbolic (encoded) score, querying the score by playing notes on a musical instrument digital interface (MIDI) keyboard, creating diagrams of the musical form, and navigating the score while comparing recordings. ${ }^{3}$ Although this prediction has not been fully realized, there has been some headway in this direction. This study investigates the current landscape of digital music libraries in Canada, specifically whether the designs and technologies meet the needs of librarians in collecting,

Meghan Goodchild (meghan.goodchild@queensu.ca) is a research data management systems librarian at Queen's University in Kingston, Ontario. Meghan received the First-Time Presenter Award at CAML's 2016 conference for this paper, which is based on research she conducted while completing the MISt program at McGill University.

\section{(2) $(1) \Theta$}

This work is licensed under a Creative Commons Attribution-NonCommercial 4.0 International License.

1. David Bainbridge, Michael Dewsnip, and Ian H. Witten, "Searching Digital Music Libraries," in Digital Libraries: People, Knowledge, and Technology (Springer e-book, 2002); lan H. Witten, David Bainbridge, and David M. Nichols, How to Build a Digital Library (Amsterdam: Morgan Kaufmann, 2010).

2. Witten, Bainbridge, and Nichols, How to Build a Digital Library, 7.

3. Jon W. Dunn et al., "Variations2: Retrieving and Using Music in an Academic Setting," Communications of the ACM 49, no. 8 (2006): 53-58. 
preserving, organizing, and disseminating diverse types of musical materials. To answer this research question, the author conducted an online survey targeting current members of the Canadian Association of Music Libraries, Archives and Documentation Centres (CAML). Quantitative and qualitative analyses of the survey responses reveal the challenges and barriers experienced, as well as the perceived benefits of incorporating technologies from Music Information Retrieval (MIR) and linked data.

\section{Literature Review}

Over the past few decades, there have been extensive efforts to digitize collections of materials used to represent musical data in various formats, such as text (e.g., lyrics), images (e.g., scanned music scores), audio (e.g., recorded music), audiovisual (e.g., recorded video performances), and symbolic notation (e.g., digital encoding of score data). ${ }^{4}$ Online digital collections aim to offer users greater discovery of and access to library materials compared with physical items. To combat against "silos" of individual digital collections, the recent development of library discovery layers provides tools for users to search across physical and online resources of local library as well as external resources. ${ }^{5}$ However, challenges continue to exist related to structuring and integrating diverse data types in a digital music library context. ${ }^{6}$ In current systems, such as the International Music Score Library Project (IMSLP) (http://imslp.org/) and the Julliard Manuscript Collection (http://juilliardmanuscriptcollection.org/), the predominant database technology is text-based, using metadata to link documents. ${ }^{7}$ Existing systems continue to have many drawbacks, particularly the lack of simultaneous presentation of related musical resources, such as alignment between scores and recordings. ${ }^{8}$

The multidisciplinary field of Music Information Retrieval (MIR) is concerned with extracting meaningful information from music, often with the aim of developing search and retrieval systems. ${ }^{9}$ One of the focuses of MIR researchers is to develop content-based approaches (i.e., tools that

4. David Damm et al., "A Digital Library Framework for Heterogeneous Music Collections: From Document Acquisition to Cross-Modal Interaction," International Journal on Digital Libraries 12, no. 2 (2012): 53-71.

5. Kirstin Dougan, "Music Information Seeking Behavior: Then and Now," in Trends in Information Seeking, Behavior, and Retrieval for Creativity, ed. Petros Kostagiolas, Konstantina Martzoukou, and Charilaos Lavranos (Hershey, PA: IGI Global, 2016), 42-57.

6. See for example: David Bainbridge, Xiao Hu, and J. Stephen Downie, "A Musical Progression with Greenstone: How Music Content Analysis and Linked Data Is Helping Redefine the Boundaries to a Music Digital Library," in 1st International Workshop on Digital Libraries for Musicology (DLfM '14) (New York: ACM, 2014), 1-8; Damm et al., "A Digital Library Framework for Heterogeneous Music Collections: From Document Acquisition to Cross-Modal Interaction"; Andrew Hankinson, Laurent Pugin, and Ichiro Fujinaga, "Interfaces for Document Representation in Digital Music Libraries," in Proceedings of the 10th International Conference on Music Information Retrieval (ISMIR) (Kobe, Japan: ISMIR, 2009), 39-44.

7. Bainbridge, Hu, and Downie, "A Musical Progression with Greenstone: How Music Content Analysis and Linked Data Is Helping Redefine the Boundaries to a Music Digital Library."

8. Hankinson, Pugin, and Fujinaga, "Interfaces for Document Representation in Digital Music Libraries."

9. Markus Schedl, Emilia Gomez, and Julian Urbano, "Music Information Retrieval: Recent Developments and Applications," Foundations and Trends in Information Retrieval 8, no. 2-3 (2014): 127-261. 
extract intrinsic properties from musical audio, related to pitch, rhythm, timbre, and other parameters), including multimodal search mechanisms, using both user-produced queries (e.g., "query by humming" ${ }^{10}$ ) and audio queries (e.g., audio fingerprinting ${ }^{11}$ ). However, these developments have not been fully integrated within large, user-facing digital music libraries. ${ }^{12}$ Several custom-made solutions for library-led projects have revealed the potential for incorporating MIR technologies. For example, the "Variations" project, developed at Indiana University, allows users to stream audio and view encoded scores with annotation tools for teaching and learning, thereby incorporating library catalogue tools and MIR technology within a digital music library context. ${ }^{13}$ The PROBADO Digital Library Initiative is a research effort to combine multimodal content-based music queries, such as full-text lyrics and audio fingerprinting. ${ }^{14}$ As another example, Bainbridge, $\mathrm{Hu}$, and Downie have demonstrated the capability of a digital music library for musicological research using "Greenstone," an open-source digital library toolkit, audio-based content analysis from MIR, and linked open data. ${ }^{15}$ To develop useful features for digital music libraries, it is important to study the current information needs and behaviours of users. However, the system-centred approach of MIR research has only recently recognized the need to understand users' needs and behaviours, and these user studies have not made a strong impact on the field. ${ }^{16}$

Although there has been an increasing number of studies of general users of information systems, very little research has been conducted on the unique information needs and behaviour of music researchers in library contexts. ${ }^{17}$ Compared with general library use, music information behaviour related to finding and retrieving materials is more complex; in addition to books and journals, users require other types of resources, such as recordings and scores. ${ }^{18}$ Moreover, locating musical materials is more challenging, as there may be multiple manifestations of a work, the subject of an

10. Bryan Pardo, Jonah Shifrin, and William Birmingham, "Name That Tune: A Pilot Study in Finding a Melody from a Sung Query," Journal of the American Society for Information Science and Technology 55, no. 4 (2004): 283300.

11. Avery Wang, "The Shazam Music Recognition Service," Communications of the ACM 49, no. 8 (2006): 4448.

12. Bainbridge, Hu, and Downie, "A Musical Progression with Greenstone: How Music Content Analysis and Linked Data Is Helping Redefine the Boundaries to a Music Digital Library."

13. Dunn et al., "Variations2: Retrieving and Using Music in an Academic Setting."

14. Damm et al., "A Digital Library Framework for Heterogeneous Music Collections: From Document Acquisition to Cross-Modal Interaction."

15. Bainbridge, Hu, and Downie, "A Musical Progression with Greenstone: How Music Content Analysis and Linked Data Is Helping Redefine the Boundaries to a Music Digital Library."

16. Jin Ha Lee and Sally Jo Cunningham, "Towards an Understanding of the History and Impact of User Studies in Music Information Retrieval," Journal of Intelligent Information Systems 41, no. 3 (2013): 499-521.

17. Katie Lai and Kylie Chan, "Do You Know Your Music Users' Needs? A Library User Survey That Helps Enhance a User-Centered Music Collection," The Journal of Academic Librarianship 36, no. 1 (2010): 63-69; Dougan, "Music Information Seeking Behavior: Then and Now."

18. Kirstin Dougan, "Information Seeking Behaviors of Music Students," Reference Services Review 40 (2012): 558-73; David M. King, "Catalog User Search Strategies in Finding Music Materials," Music Reference Services Quarterly 9, no. 4 (2007): 1-25. 
item may not be apparent, and the printed title may be different from the original title. ${ }^{19}$ Concerns have been raised regarding new discovery layers and next-generation catalogues in terms of the ability of users to retrieve all iterations and manifestations of a musical work and the ability to apply uniform titles. ${ }^{20}$ Keyword searching is often the most beneficial approach, as the pertinent information is often stored in a content note, added entry, or another field. ${ }^{21}$ Additionally, the search strategies of users can vary based on research expertise; users with limited experience have been found to have difficulty expressing their needs and rely more on browsing. ${ }^{22}$ Users have reported frustration when filtering query results using facets. ${ }^{23}$

Several studies indicate that digital libraries should support the complexity of music-information behaviour in research. Based on interviews with users of a folk music library, Inskip et al. recommend designing a digital library system that provides background information, enables browsing, provides links between resources, allows direct access to digital sound files, and facilitates connections to other information sources. ${ }^{24}$ Given that music researchers draw on diverse sources of information, Barthet and Dixon recommend that future systems should have the capability of linking music documents and representations (i.e., aural, visual, textual, and symbolic information), a functionality which could be achieved via semantic web technologies with linked data. ${ }^{25}$ Additionally, they propose that content-based MIR techniques could support research by being incorporated into software for listening to recordings and for viewing scores simultaneously. ${ }^{26}$ Based on a survey of musicologists, Inskip and Wiering suggest that efforts should be made to

19. Anita Breckbill, "The Trial of Searching for Musical Works Using Resource Discovery Tools," in Planning and Implementing Resource Discovery Tools in Academic Libraries, ed. M. Pagliero Popp and D. Dallis (Hershey, PA: Information Science Reference, 2012), 662-76; Kirstin Dougan, "Finding the Right Notes: An Observational Study of Score and Recording Seeking Behaviors of Music Students," The Journal of Academic Librarianship 41, no. 1 (2015): 61-67; King, "Catalog User Search Strategies in Finding Music Materials."

20. Breckbill, "The Trial of Searching for Musical Works Using Resource Discovery Tools"; Tracey Snyder, "Music Materials in a Faceted Catalog: Interviews with Faculty and Graduate Students," Music Reference Services Quarterly 13, no. 3/4 (2010): 66-95.

21. Dougan, "Finding the Right Notes: An Observational Study of Score and Recording Seeking Behaviors of Music Students"; Margaret Hume, "Searching for Media in the Online Catalog: A Qualitative Study of Users," The Journal of Academic Media Librarianship 3, no. 1 (1995): 1-28; King, "Catalog User Search Strategies in Finding Music Materials."

22. Charles Inskip, Richard Butterworth, and Andrew MacFarlane, "A Study of the Information Needs of the Users of a Folk Music Library and the Implications for the Design of a Digital Library System," Information Processing and Management 44, no. 2 (2008): 647-62.

23. Dougan, "Finding the Right Notes: An Observational Study of Score and Recording Seeking Behaviors of Music Students."

24. Inskip, Butterworth, and MacFarlane, "A Study of the Information Needs of the Users of a Folk Music Library and the Implications for the Design of a Digital Library System."

25. Mathieu Barthet and Simon Dixon, "Ethnographic Observations of Musicologists at the British Library: Implications for Music Information Retrieval," in Proceedings of the 12th International Society for Music Information Retrieval Conference (ISMIR 2011) (Miami, Florida: ISMIR, 2011), 353-58.

26. Barthet and Dixon, "Ethnographic Observations of Musicologists at the British Library: Implications for Music Information Retrieval." 
develop user-centred software that supports their research workflows, particularly by providing comprehensive online access to digital resources. ${ }^{27}$

The few user studies in MIR tend to focus on general music information behaviour (outside of academic contexts), but the results also provide insight into designing these systems. Based on a large-scale user survey of music information needs and information-seeking behaviours, Lee, Cho and Kim found that serendipitous discovery in music services was the most important feature, which they suggest could be potentially incorporated into digital library systems. ${ }^{28}$ Lee et al. also reported that many users demonstrated a strong desire to learn about the background and musical context, a behaviour that supports the idea that systems should represent relationships among genres, artists, and musical works, as well as provide semantic links to other resources. ${ }^{29}$

The expertise of music librarians is noticeably scarce in this discussion. A recent interview study on digitizing musical scores revealed that librarians face challenges related to short-term funding, creating metadata, skilled staff support, and the use of various technologies such as Optical Music Recognition (OMR). ${ }^{30}$ Further research is needed to understand librarians' experiences with other stages of digital music library projects. What types of materials are included in library-hosted digital music libraries and how are they integrated? Are librarians aware of the users' experiences? What is their view of the future of digital music libraries?

\section{Present Research}

The aim of the work presented here was to investigate an overarching research question: How do the current designs and structures of digital music libraries meet the needs of librarians in preserving, collecting, organizing, and disseminating diverse types of music documents? The research reported here investigates the current types of digital materials (e.g., audio, video, text, scores) that are included in local digital music collections and how they are hosted and accessed. The project explores the challenges or barriers that music librarians face in hosting digital collections, their perceptions and knowledge of their patrons' usage of digital collections, as well as the developments in MIR and linked data technologies that would be beneficial for librarians and users in a digital music library context. The research responds to the recent developments within these fields and the growing interest in the potential of digital music libraries.

27. Charles Inskip and Frans Wiering, "In Their Own Words: Using Text Analysis to Identify Musicologists Attitudes Towards Technology," in Proceeedings of the 16th International Society for Music Information Retrieval Conference (ISMIR) (Malaga, Spain, 2015), 455-61.

28. Jin Ha Lee, Hyerim Cho, and Yea-Seul Kim, “Users' Music Information Needs and Behaviours: Design Implications for Music Information Retrieval Systems," Journal of the Association for Information Science and Technology, 2015, 1-30.

29. Lee, Cho, and Kim, "Users' Music Information Needs and Behaviours: Design Implications for Music Information Retrieval Systems."

30. Audrey Laplante and Ichiro Fujinaga, "Digitizing Musical Scores: Challenges and Opportunities for Libraries," in Proceedings of the 3rd International Workshop on Digital Libraries for Musicology (DLfM 2016) (New York, NY, 2016), 45-48. 


\section{Methods}

To investigate the exploratory research question, a survey instrument was designed with both quantitative questions (e.g., multiple-choice, Likert scales) and qualitative questions (free-response format). A web-based survey was selected in order to reach the largest sample of the population and to collect information that could describe the current status of the population. Four sections of the survey covered questions concerning the demographics of the participants ("About you"), digital collections related to participants' library or organization ("About your library"), experiences with and perceptions of their patrons and users ("About your patrons"), and the current status and future of digital libraries ("About digital libraries in general and future designs"). The survey questions are presented in the Appendix. The McGill Research Ethics Board reviewed and approved the project in accordance with McGill University Policy on the Ethical Conduct of Research Involving Human Participants.

The survey was pre-tested with two music librarians and one music library staff member. The pretest involved a think-aloud protocol which was audio recorded for subsequent analysis. Based on the reliability and validity of these responses, the survey questions were modified for clarity and comprehension. The survey was administered with LimeSurvey, an online survey tool that is hosted on a McGill University server. Two students in the Master of Information Studies program at McGill University piloted the online survey to ensure proper functionality.

The target population included members of the Canadian Association of Music Libraries, Archives and Documentation Centres (CAML), who are professionals at a variety of organizations that support musical activities across Canada. Participants were recruited by emailing the CAML listserv, which was estimated to have 70 registered members in 2016. A separate email invitation in French was sent to the Quebec chapter of CAML, the Section québécoise de l'Association canadienne des bibliothèques, archives et centres de documentation musicaux (SQACBM). The survey link was emailed individually to interested members. Participants read the online informed consent form and accepted before proceeding with the survey. On the last page of the survey, participants were asked if they would like to volunteer to be interviewed for a later study. Their email address was not associated with any survey answers. The survey was open in March and April of 2016.

The survey responses were downloaded into a CSV spreadsheet. All data collected from the survey were coded and de-identified. Incomplete responses were removed. Summary analyses for quantitative data were calculated in Excel (Microsoft). Free-text responses were analyzed using a qualitative approach developed by sociologists following grounded theory, an inductive method used to discover emerging themes from the texts without prior assumptions. ${ }^{31}$ Through an iterative

31. Giampietro Gobo, Doing Ethnography (London: Sage, 2008); Barney G. Glaser and Anselm L. Strauss, The Discovery of Grounded Theory: Strategies for Qualitative Research (New York, NY: Adeline de Gruyter, 1967). 
process, themes were identified, combined, altered, or removed, reflecting patterns and common ideas that best represent the responses. ${ }^{32}$

\section{Results}

About you

A total of 20 participants completed the survey, a response rate of $28.6 \%$ of registered CAML members. The first section covered demographic questions. The participants reported working at libraries (17), a museum (1), a university (1), and a private company (1) for an average of 10.6 years $(S D=8.40)$. The job titles that were provided by participants indicate their expertise as information professionals, including mainly music librarians (65\%), but also including senior university and library administrators, faculty members, a library assistant, and a volunteer. To preserve the anonymity of the participants, the names of organizations and institutions will not be reported here. These organizations and institutions are located across Canada, including the provinces of British Columbia, Alberta, Manitoba, Ontario, and Quebec (5 abstentions).

\section{About your library}

The second section of questions was concerned with digital collections related to music that the participants' library or organization directly owns and hosts. The distinction between "digital collection" and "digital library" remains vague in the literature; the former often refers to the raw materials, and the latter to the full system, but the two terms are often used interchangeably. ${ }^{33}$ Based on the responses to the pre-tests, survey responders would likely be more familiar with the term digital collection in relation to their own library or organizational context. Therefore, this term was selected for the first section of the survey, but digital library was employed in the later sections when referring to large-scale systems.

In total, $75 \%$ of participants reported that their library or organization hosts digital collections. Figure 1 presents the responses relating to the types of materials included in the collection (check all that apply). As shown, $87 \%$ of respondents indicated that these collections include audio and text. Only $13 \%$ of participants reported that their collections include symbolic or machine-readable scores, such as MIDI or MusicXML. Participants also listed archival materials, such as images, concert programmes, and correspondences. In terms of the manner in which libraries host their collections, some $60 \%$ of participants reported that digital collections are housed on library hosted websites and $67 \%$ reported that the collections are housed on external websites, such as the Internet Archive (https://archive.org) or Flickr (https://flickr.com). More than half of the participants (60\%) reported that the collection was integrated with library catalogue discovery

32. Eric P. S. Baumer et al., "Comparing Grounded Theory and Topic Modeling: Extreme Divergence or Unlikely Convergence," Journal of the Association for Information Science and Technology 68, no. 6 (2017): 13971410.

33. Clifford Lynch, "Digital Collections, Digital Libraries and the Digitization of Cultural Heritage Information," First Monday 7, no. 5 (2002). 
tools. In terms of access, $67 \%$ of participants reported that digital collections are available only to library patrons, and $80 \%$ reported that the collections had open access.

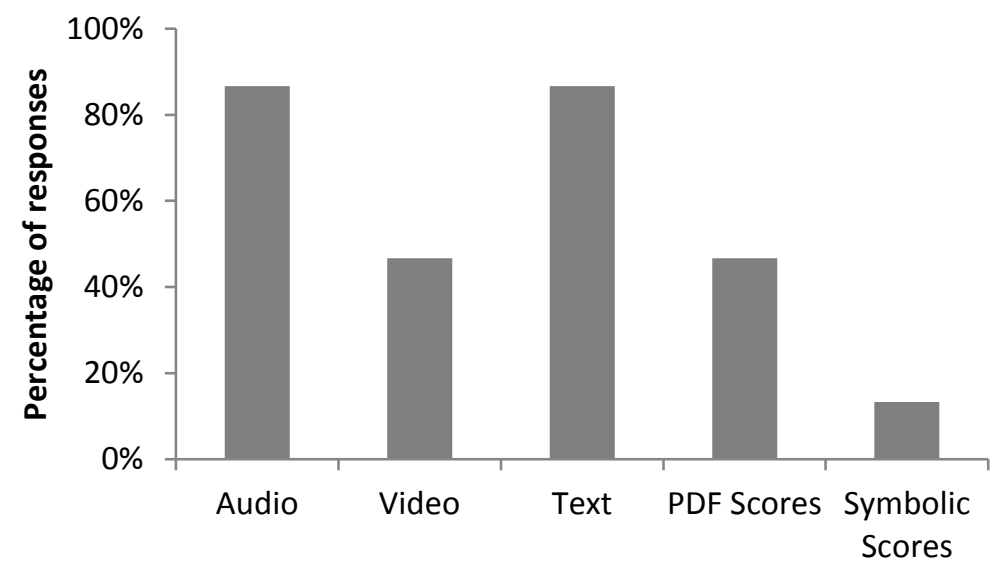

Figure 1. Responses to Question 6, "What kind of digital collections does your library host? (check all that apply)"

Recent efforts in MIR and within library catalogue systems have focused on the ability to integrate collections of music documents so that a single search can return multiple manifestations. ${ }^{34}$ Figure 2 presents the responses for this characterization of the collections. In total, $53 \%$ of participants indicated that the collection contained a single type of music representation. Only $27 \%$ indicated that diverse music representations are integrated through text-based metadata, and $27 \%$ indicated content-based access (i.e., using tools that extract intrinsic properties from musical audio, such as multimodal search mechanisms).

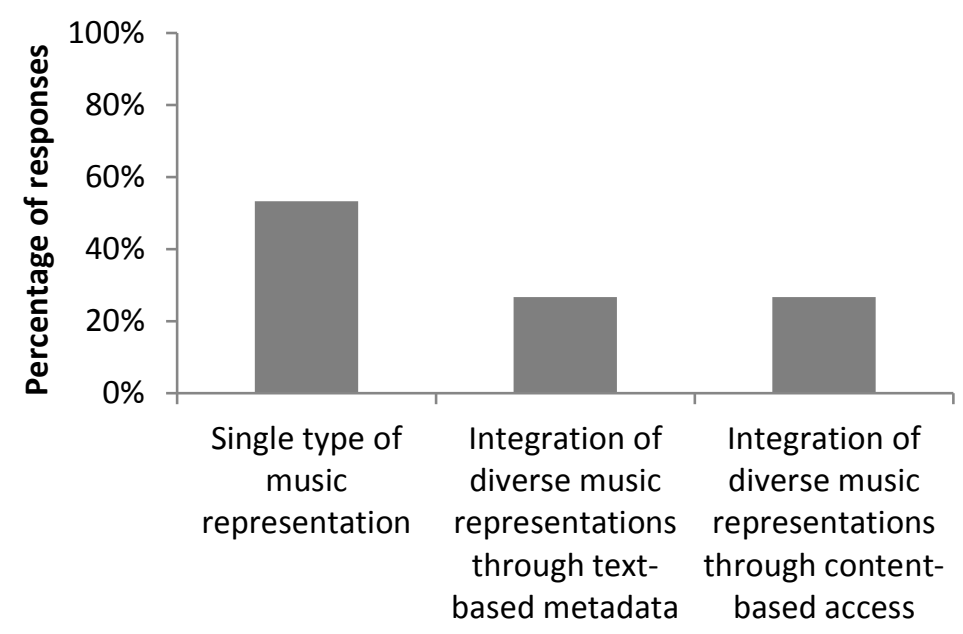

Figure 2. Responses to Question 10, "How would you characterize your digital collections? (check all that apply)"

34. Schedl, Gomez, and Urbano, "Music Information Retrieval: Recent Developments and Applications"; Dougan, "Music Information Seeking Behavior: Then and Now." 
The 15 participants who indicated that their library or organization owns or hosts digital collections were asked to rank ( 1 = highest, 7 = lowest) the challenges that their organizations encountered. Those whose library or organization does not own or host digital collections (five participants) were asked to rank the barriers preventing them from doing so. Table 1 presents the average rankings related to the challenges and barriers for each reason given. The standard deviation is provided as a measure of the variation of the data values. For the participants who host collections, the largest challenges include budgetary $(M=2.83)$ and staff support $(M=3.25)$, whereas the lower ranked challenges include interface design $(M=5.08)$ and technology (hardware) $(M=5.08)$. For those who do not host collections, the main reason is budgetary, which was consistently ranked as a major challenge, followed by staff support $(M=3.50)$ and technology (hardware) $(M=3.75)$. The lower ranked barriers include functionality issues $(M=5.00)$ and technology (software) $(M=5.25)$.

Table 1. Mean rankings and standard deviations for the challenges and barriers for hosting digital collections.

\begin{tabular}{lllll}
\hline & \multicolumn{2}{l}{ Host collections $(n=15)$} & \multicolumn{2}{l}{ Do not host collections $(n=5)$} \\
\hline Type & $M$ & $S D$ & $M$ & $S D$ \\
\hline Budgetary & $\mathbf{2 . 8 3}$ & $\mathbf{2 . 2 9}$ & $\mathbf{1 . 7 5}$ & $\mathbf{0 . 5 0}$ \\
Copyright & 4.25 & 2.38 & 4.00 & 2.16 \\
Functionality issues & 3.75 & 1.60 & 5.00 & 0.82 \\
Interface design & 5.08 & 1.56 & 4.75 & 1.71 \\
Staff support & 3.25 & 2.18 & 3.50 & 2.52 \\
Technology (hardware) & 5.08 & 1.44 & 3.75 & 2.63 \\
Technology (software) & 3.75 & 1.71 & 5.25 & 2.06 \\
\hline
\end{tabular}

Note. Values are means $(M)$ of the reported rankings ( 1 = highest rank, 7 = lowest rank) and the standard deviations (SD). Bold text indicates the highest average value for each group.

The participants were provided with an option to elaborate on any challenges encountered in hosting digital collections. Three themes emerged from text analysis related to organizational restrictions, copyright, and individualized solutions. In terms of organizational issues, several participants discussed problems encountered with centralizing digital collections at university libraries, which have implications for obtaining resources for music-oriented collections. One respondent noted that curating digital collections requires not only an initial time investment, but ongoing interdepartmental collaboration; however, digital collection projects may not be a top priority at the organizational level. Participants also discussed copyright issues, such as establishing the legal and technical infrastructure to support purchased audio files that may not be specifically licensed for digital collection projects. The challenges inherent in the complexity of digital music collections often result in the need for individualized solutions. Some participants reported 
difficulties in finding solutions and services related to a specific collection, often relying on outside vendors for certain projects (e.g., Flickr), or creating tailor-made designs.

The participants who reported that their library or organization does not host any digital collections were also asked to elaborate on barriers experienced. The same three themes emerged related to organizational restrictions, copyright, and individualized solutions. Again, several participants reported issues related to the centralization of digital collections at their library. As a result, participants report a lack of budget, resources, server space, and staff support for digital collection projects related to music. Although digital initiatives may be taking place at a broader organizational level, several responders reported that the possibilities for music collections are not a priority. Copyright issues, such as controlling the access for institutional patrons only, are also problematic for several responders. One participant noted the need for support from the administration and music department to assist in managing rights for student performances, for example. As reported above, the design of a tailor-made solution may be prohibitive for libraries. Given the complexity of digital music collections, a small project may not be worth the time and effort for ostensibly little net gain.

\section{About your patrons}

The third set of questions related to the participants' experiences with and perceptions of their library patrons (i.e., users of the digital collections). These questions were presented on 5-point Likert scales with one neutral, two positive, and two negative positions. Participants could also opt to skip the question. Figure 3 presents the percentage of responses indicating their perception of the extent to which patrons are aware of the digital collections hosted by the library. The results indicate that librarians judge patrons' awareness as quite low in general, with the majority ranging from somewhat aware (neutral) to completely unaware. Figure 4 presents the percentage of responses indicating the extent to which patrons are aware of digital collections or digital libraries that are open access or part of a library subscription. Comparing Figures 3 and 4, patrons' awareness of digital collections or digital libraries that are open access or part of a library subscription is marginally higher. Although the participants consider that the awareness of digital collections is moderate, they perceive that patrons' satisfaction of available digital collections or digital libraries is relatively high, as shown in Figure 5. However, almost half of the respondents were unsure of the level of satisfaction of their patrons. 


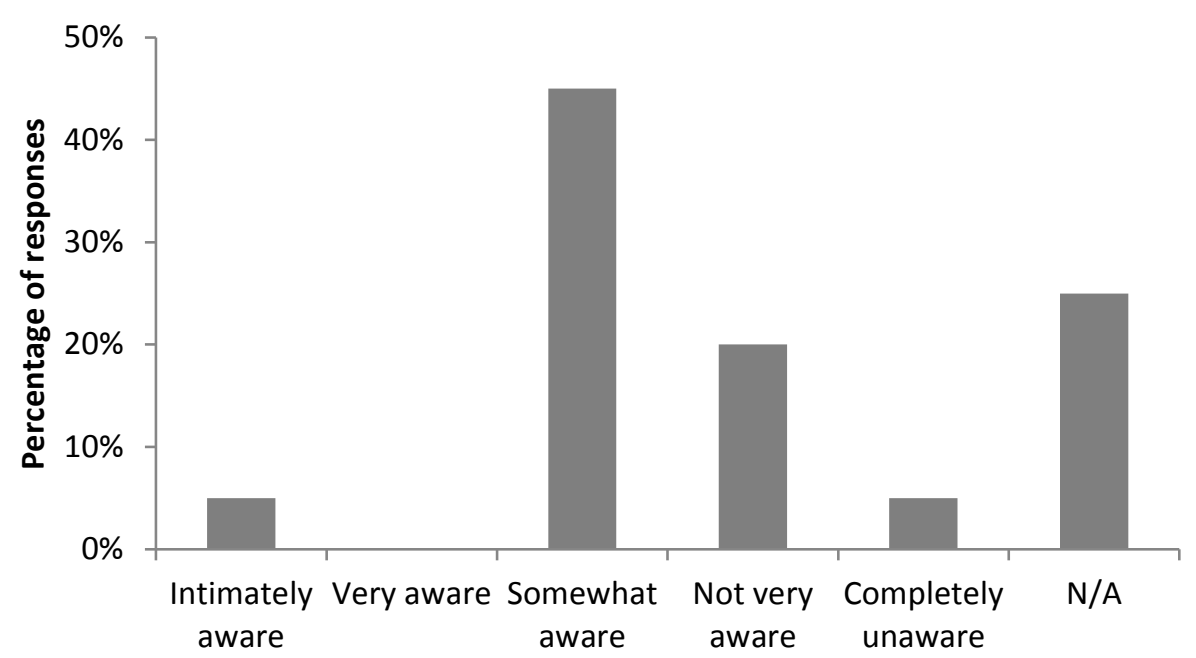

Figure 3. Responses to Question 15, "To what extent are your library patrons aware of the digital collections that your library hosts?"

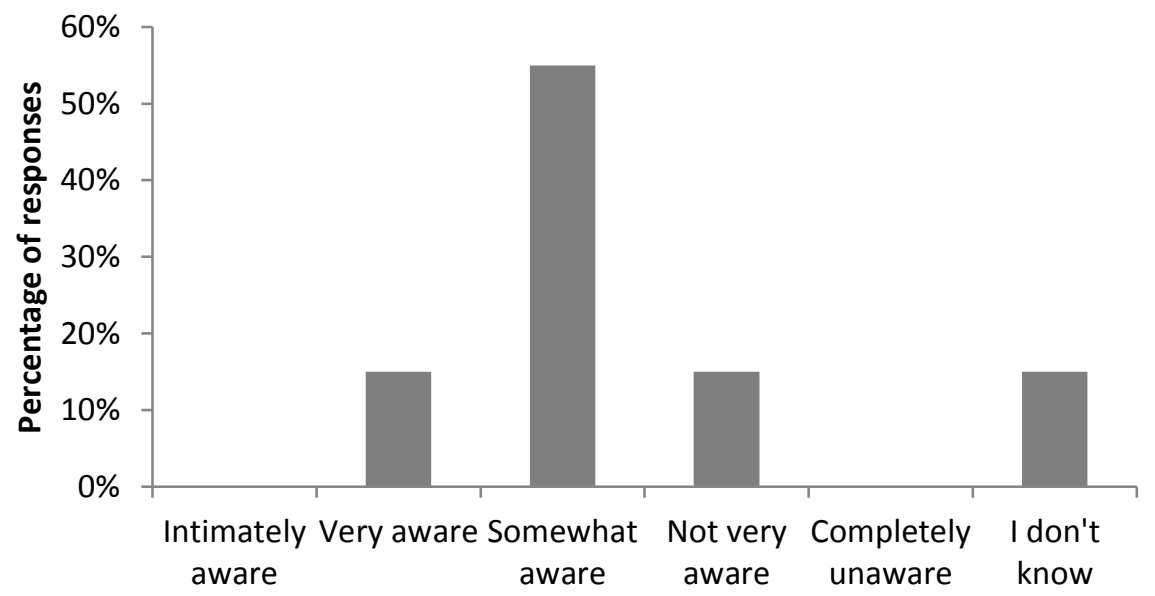

Figure 4. Responses to Question 16, "To what extent are your patrons aware of digital collections or digital libraries that are open access or that your library subscribes to?" 


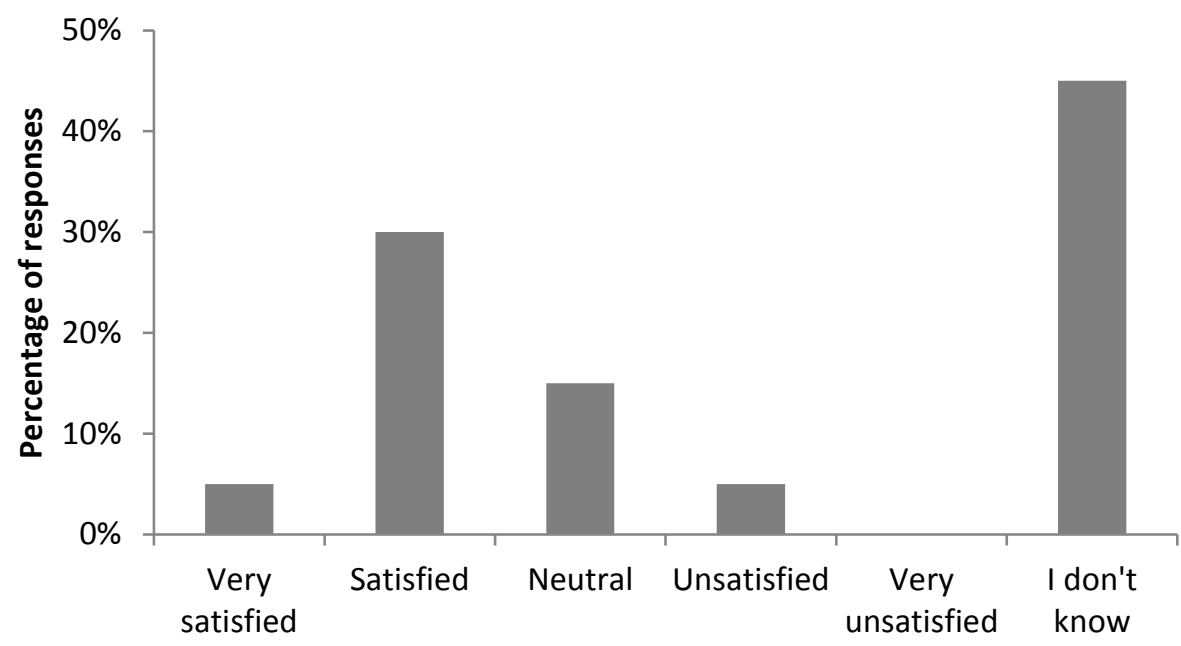

Figure 5. Responses to Question 17, "How satisfied are your patrons with available digital collections or digital libraries?"

When asked about the importance of digital collections or digital libraries to their patrons for research, $80 \%$ of responses ranged from somewhat important to extremely important (Figure 6). Participants were asked whether the following interface functionalities were important for information seeking: browsing, quick search, advanced search, and faceted navigation. As shown in Figure 7, most participants indicated the importance of quick search, with 75\% "yes" responses. The responses for faceted navigation were tied, with $50 \%$ yes and no.

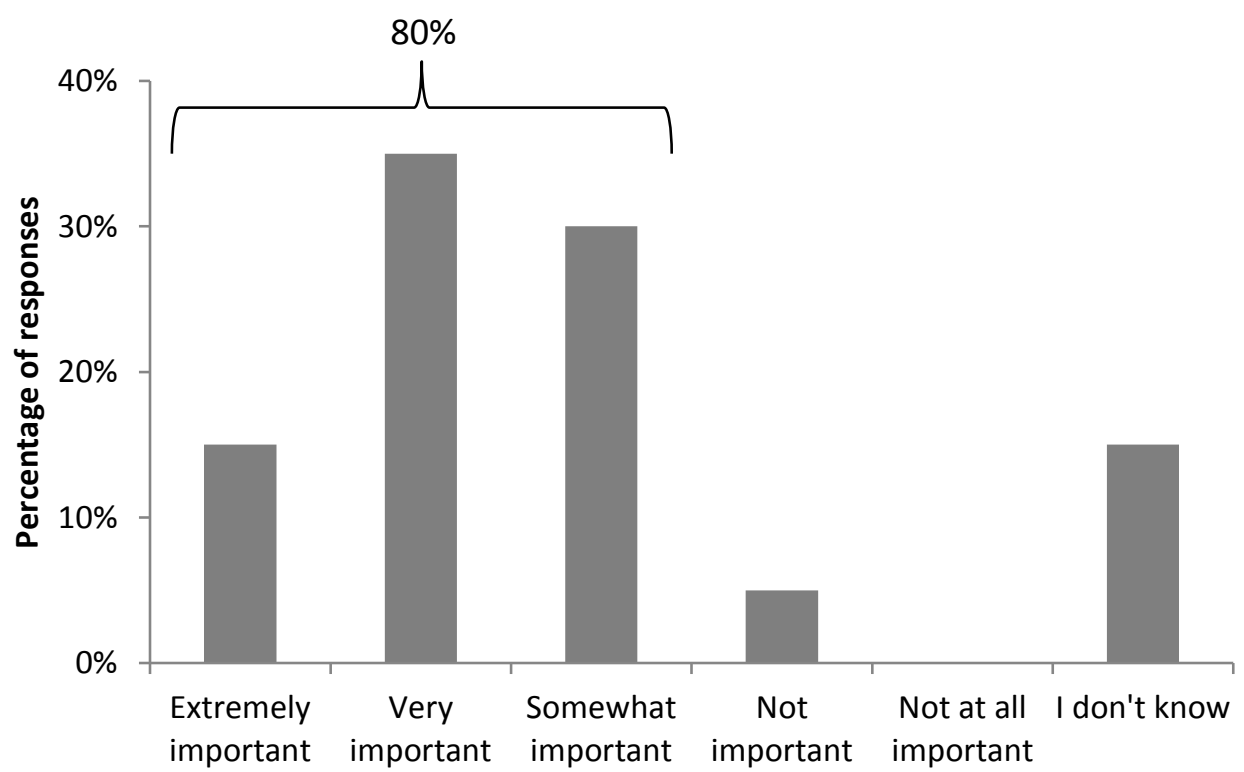

Figure 6. Responses to Question 18, "How important are digital collections or digital libraries to your patrons for research?" 


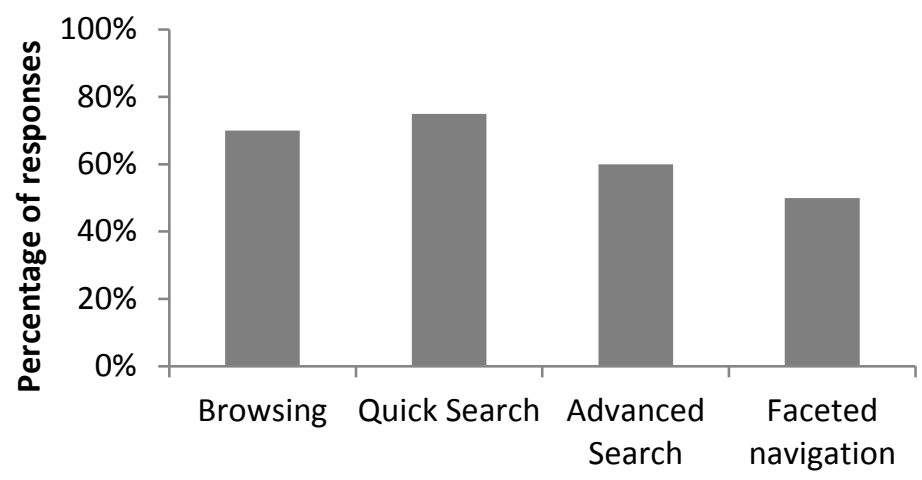

Figure 7. Responses to Question 19, "What types of functionalities for information-seeking are important for your patrons? (select all that apply)"

The respondents were invited to comment if their patrons reported any issues related to functionality with or access to digital collections or digital libraries. $65 \%$ of the participants left no response or responded "no." Based on the content analysis of the open-ended responses, functionality problems appear to arise when users attempt to use the system for tasks for which it was not designed. For example, one participant indicated that users often want to create reports or statistics based on the information stored within the collection, but this would only be possible from the back end of the database. Another participant indicated that users experience printing problems for sheet music collections, which were likely designed to be viewed on screen. Functionality problems were also reported in relation to information retrieval. One participant indicated that patrons complained about the simplification of search capabilities for digital collections, such as Eighteenth Century Collections Online (http://quod.lib.umich.edu/e/ecco/). In terms of access, users report issues when the content is missing due to link rot and when it is removed by the library or one of the content providers. Users also experience problems with streaming audio as a result of server lags.

Participants had the opportunity to comment about their patrons' use of digital collections in general, which resulted in a 30\% response rate. Two themes emerged from analysis of the responses of participants: organizational issues and challenges related to individualized solutions. One participant reiterated the organizational issues in hosting digital collections. Although digital curation and preservation may be articulated in long-term strategic plans, challenges continue to exist in terms of infrastructure, expertise, and human resources. Several participants indicated that the diversity of needs and the number of collections are growing. Therefore, individualized solutions cannot keep up with demand. Respondents indicate there are too many different collections available for users, who will often opt for non-library tools and collections, such as YouTube (www.youtube.com) for quick access to music recordings, rather than struggle with subscription services (e.g., Naxos Music Library). 
About digital libraries in general and future designs

The final section of the survey related to digital libraries and their future designs. Figure 8 presents the participants' past involvement with designing digital collections or digital libraries. About half (55\%) of responses indicated that the participants have previously been involved, intimately involved, or occupied the role of lead designer. Only $35 \%$ had not been involved in any capacity. As shown in Figure $9,80 \%$ of participants would be interested or very interested in participating in the design of digital libraries in the future.

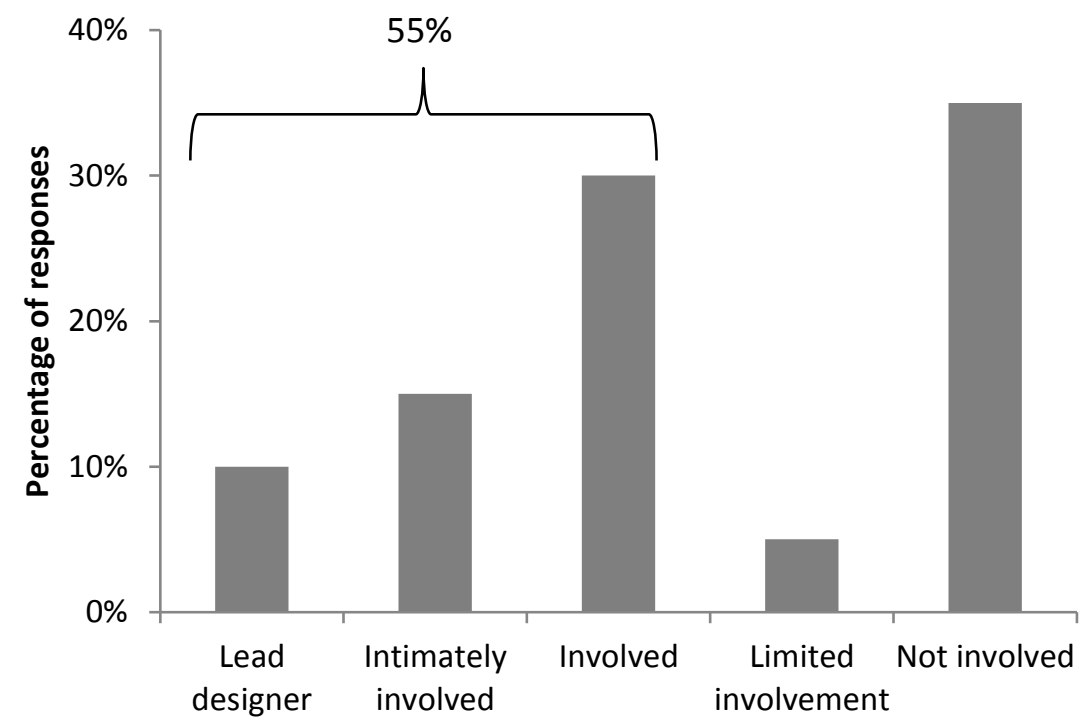

Figure 8. Responses to Question 22 “Have you been involved with designing digital collections or digital libraries? (check all that apply)"

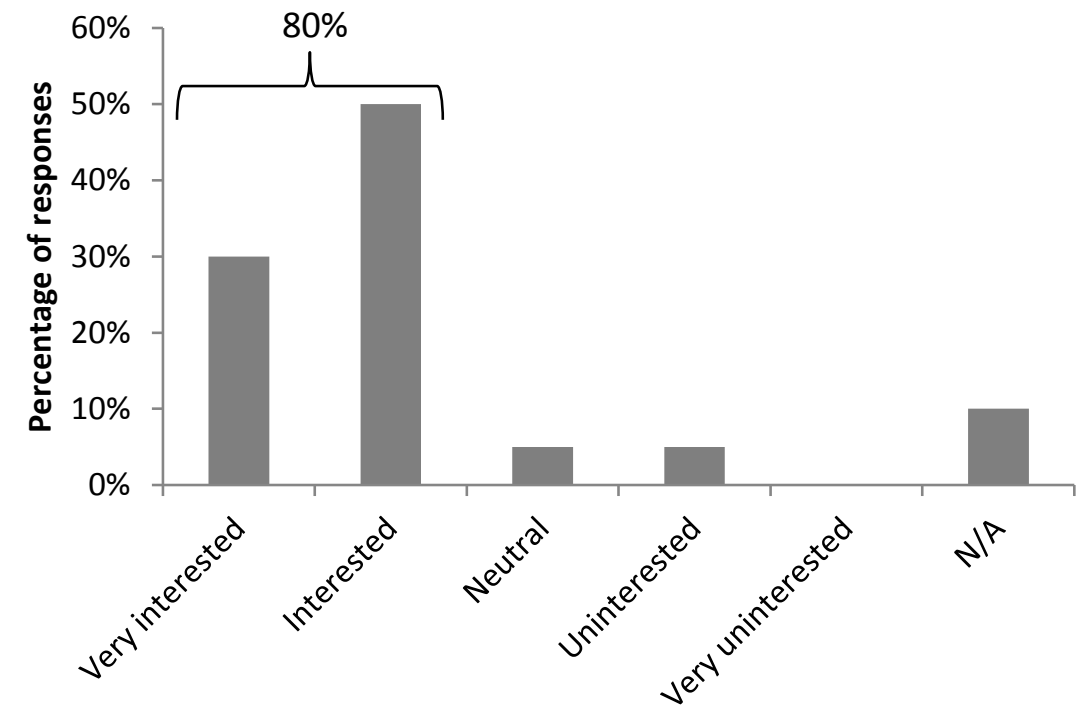

Figure 9. Responses to Question 23 "Would you be interested in participating in the design of digital libraries in the future?" 
Participants were given a selection of recent advances in MIR and linked data and asked their opinions regarding how beneficial each one would be to incorporate into digital libraries.

Participants responded on a 5-point scale from "Very beneficial" to "Not at all beneficial." Figure 10 presents the percentage of responses for each technology (shown along x-axis) grouped into positive (i.e., very beneficial and beneficial) and neutral/negative (i.e., neutral, not beneficial). No participants selected "Not at all beneficial." The technologies included serendipitous discovery processes; visualizations of search results and data; search by audio snippet; query-by-humming $(\mathrm{QBH})$; search by similarity (content-based approach); relationships between genres, artists, works, topics shown through semantic links; collaborative social features (e.g., playlist creation); and multimodal interface integration and alignment. Black shading represents positive responses, and grey shading represents neutral/negative responses. A few participants (10\%) answered "I don't know" for all of the technologies. Overall, there appears to be less consensus for searching by audio snippet and QBH based on the range of responses for these features (45\% positive and $45 \%$ neutral/negative responses). Generally, positive responses were provided for the other technologies, particularly for semantic link relationships and multimodal interface, each with $80 \%$ positive responses.

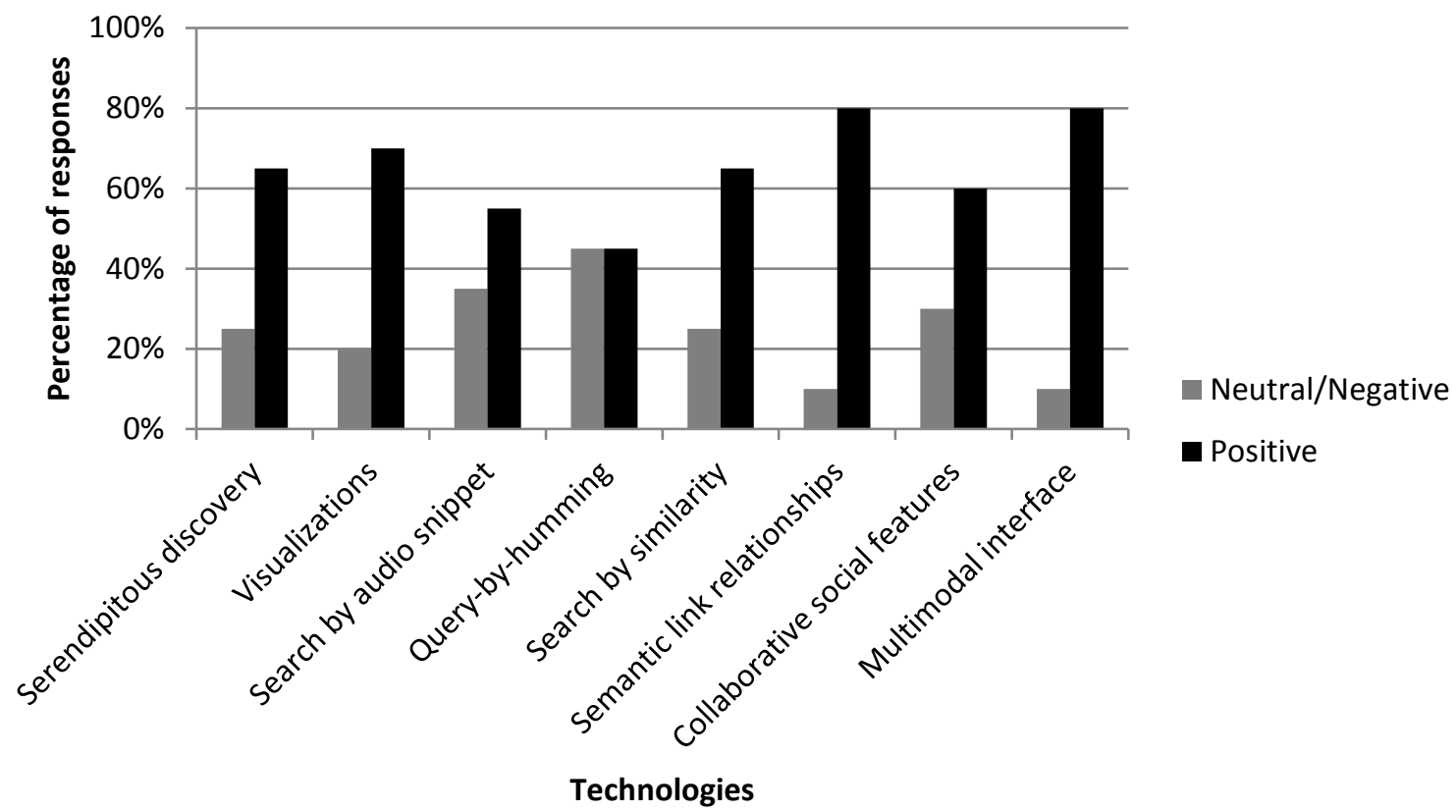

Figure 10. Responses grouped into neutral/negative and positive answers to Question 24 "To what extent would the following Music Information Retrieval (MIR) techniques and linked data technologies be beneficial to incorporate into digital libraries?"

Participants were invited to comment on how digital collections and digital libraries could be improved in terms of access and functionality. More than half of participants (55\%) responded with suggestions and three themes emerged based on analysis of their responses. These related to integrating collections, linked data technologies, and clarifying copyright guidelines. Participants 
most commonly suggested the need for developing mechanisms for users to search across diverse collections. Many participants indicated that housing digital collections on individual websites creates silos, making it difficult for users to know that these collections exist. Building upon these points, several participants mentioned the possibility of drawing on linked data technologies, thereby standardizing the metadata in a meaningful and accurate manner to increase the discoverability and integration of these collections. One participant also reflected on some ongoing challenges with searching and retrieval techniques in the digital world, noting the difficulties of serendipitous discovery. Additionally, the search results are often too granular, which results in a loss of context. The third theme was related to the need for clear guidelines and standards for copyright material. In this vein, several participants noted a lack of leadership in Canada. Additionally, a major obstacle is finding affordable audio asset management systems, as many systems embed proprietary metadata, making it difficult to ensure long-term access.

Participants were asked for their view of the future of digital libraries. Half responded, and two major themes emerged, related to the trend towards greater online access and the need for integration of diverse musical documents. The majority of participants indicated that they expected the current digital trend to continue with increasing online access to audio, scores, text, and visualizations. Many participants envisioned the integration of these resources through linked open data. This structure would allow the retrieval of data about music from various sources and the integration of materials used for research and instruction.

\section{Discussion and Conclusion}

This paper reports the results of a survey of CAML members that investigated the extent to which the current designs and structures of digital music libraries are meeting the needs of librarians and users, and whether recent developments in MIR and linked data would be beneficial to incorporate. The response rate of $28.6 \%$ of registered members was relatively low. Although there are no standards for acceptable response rates of surveys in the social sciences, ${ }^{35}$ meta-analyses of webbased survey studies show an average response rate of $34 \%$, with a minimum of $10 \%$ and maximum of $88 \% .{ }^{36}$ Considering the difficulty of determining the nonresponse error, the results of the survey must be generalized with caution.

Overall, the majority of the participants (75\%) indicated that their library or organization hosts music-related digital collections, which mainly include audio and text. These collections are hosted both on local institutional websites and on external websites. Many collections are integrated with the library catalogue discovery tools, with open access or access for patrons only. The results reveal

35. A recent study indicates that none of the social sciences journals had written standards for response rates, and response rates in accepted publications ranged from 16\% to 91\% : Lisa R. Carley-Baxter et al., "Does Response Rate Matter? Journal Editors Use of Survey Quality Measures in Manuscript Publication Decisions," Survey Practice 2, no. 7 (2009): 1-7.

36. Tse-Hua Shih and Xitao Fan, "Comparing Response Rates from Web and Mail Surveys: A Meta-Analysis," Field Methods 20, no. 3 (2008): 249-71. 
that there were similar challenges for libraries and organizations that host digital collections and barriers preventing others from hosting. These challenges and barriers included organizational restrictions, copyright issues, and problems related to the need for individualized solutions. Since some organizations were able to overcome these challenges, there may be some solutions that could be shared. For example, one participant reported a barrier to providing access to the collection to patrons only. The survey results revealed that $67 \%$ of libraries and organizations that host digital collections restrict access to their patrons only, which suggests there are solutions available. As another example, one participant indicated that a small collection that could be digitized and shared online was likely too limited "to be worth the time and effort." However, another participant described the success of a very small collection from a single donor that was turned into a digital collection through Flickr. Therefore, these results indicate that there may be technological hurdles that could be solved in a straightforward manner through collaboration and sharing across organizations.

The participants judged patrons' awareness of digital collections and digital libraries as low in general. Respondents are also unsure about their patrons' satisfaction. In-depth interviews with librarians could uncover more details regarding their interactions with users of digital collections and digital libraries. It is likely that librarians and other staff members have not received much feedback or have not sought evaluations from users. Similarly, Puckett Sasser's survey indicated that institutions gain knowledge of their online music collections' usage mainly through informal feedback, with only $35 \%$ of institutions using formal tools such as user surveys. ${ }^{37}$ As a result, the author advises that institutions should proactively obtain feedback about the collections. In the present study, the survey responses suggest that digital collections and digital libraries are important for patrons for research. Therefore, increasing awareness of these collections and developing feedback mechanisms may be an area for improvement in libraries and organizations.

Further research is needed to identify the important functionalities for search interfaces, since there was little consensus in the survey responses. The most important functionality was identified as quick search, with $75 \%$ of participants responding in the affirmative. The responses for the importance of faceted navigation (i.e., filtering results) were evenly divided between "yes" and "no." These results relate to findings in the literature concerning library catalogue searchers. In Dougan's online survey and focus group study, users expressed frustration related to filtering and sorting search results in library catalogue interfaces. ${ }^{38}$ From the perspective of a librarian, Breckbill argues that even experienced researchers are unable to retrieve all iterations and manifestations of a musical work in a single search using current resource discovery tools. ${ }^{39}$ Although the ability to refine search results by facets is important to users, many have experienced difficulty when Library

37. Patricia Puckett Sasser, "Sounds of Silence: Investigating Institutional Knowledge of the Use and Users of Online Music Collections," Music Reference Services Quarterly 12, no. 3-4 (2009): 93-108.

38. Dougan, "Information Seeking Behaviors of Music Students."

39. Breckbill, "The Trial of Searching for Musical Works Using Resource Discovery Tools." 
of Congress Subject Headings (LCSH) and other databases are not integrated logically. ${ }^{40}$ In the present survey, one respondent revealed that their current library discovery layer actually puts users at a disadvantage when they are seeking scores and recordings. Taken together, the current functionalities of search interfaces are not meeting the needs of users, who may have the most success using a quick search query. One limitation of the present study is that the participants are responding based on their interactions with and perceptions of users. Given that the users' needs may not be fully understood, further studies are needed to connect librarians' expertise and users' needs in more detail.

Participants were asked their opinions on how beneficial it would be to incorporate new MIR and linked data technologies into digital libraries. The functions of illustrating topics through semantic links and multimodal interface integration received the most positive responses. There were mixed responses for searching by audio snippet and query by humming $(\mathrm{QBH})$, two technologies which have been a major focus of the MIR community for the past decade. ${ }^{41}$ It remains to be seen how these technologies could be combined to assist users with discovery and access. Along these lines, developing an integrated system of MIR features has been called the "Grand Challenge" of the field. ${ }^{42}$ Collaboration with librarians, users, MIR researchers, and digital library software designers would coordinate efforts and ensure that future developments will be beneficial. Whereas $55 \%$ of participants have been involved in the design of digital libraries in the past, most of the respondents $(80 \%)$ would be interested in participating in future designs, a promising outlook for future collaborations.

The final questions of the survey asked participants to comment on how to improve the access or functionality of digital collections and digital libraries, and about their views of the future of digital libraries. The main issue discussed involved the complexity of integrating diverse types of musical materials. Currently, there are many individual collections, but we are still waiting for a single "onestop" search platform. To move forward, the survey participants recommend drawing on linked data technologies and standardizing the metadata in a meaningful and accurate manner, which will increase the discoverability and integration of these collections. Major challenges continue to concern interoperability, with the need for establishing standards to facilitate the assembly of distributed digital libraries, and intellectual property, with the need to clarify copyright guidelines. In future, an interview study will be conducted to unpack these responses to better understand how to move forward with improving access and functionality of digital music libraries.

40. Snyder, "Music Materials in a Faceted Catalog: Interviews with Faculty and Graduate Students."

41. Schedl, Gomez, and Urbano, "Music Information Retrieval: Recent Developments and Applications."

42. J. Stephen Downie, Donald Byrd, and Tim Crawford, "Ten Years of ISMIR: Reflections on Challenges and Opportunities," in Proceedings of the 10th International Conference on Music Information Retrieval (ISMIR) (Kobe, Japan: ISMIR, 2009), 13-18. 
This study contributes to the ongoing research on digital music libraries, revealing the varied experiences of librarians with digital music collections across Canada and the gaps between current digital music libraries and their ideal functionalities. This research also outlines the complexity of the issues for music librarians and points to the need for leadership in Canada. Currently, the unique situations at individual institutions ultimately dictate their capabilities in terms of digital library projects. One suggestion would be to build on shared experiences, pooling solutions to common challenges or barriers in order to move forward. There is also a need to conduct further collaborative studies and contribute to ongoing interdisciplinary avenues. ${ }^{43}$ It is still unclear what the future of a musical query within a digital music library will look like or whether the predictions of Dunn et al. will come to fruition. ${ }^{44}$ Undoubtedly, advancements in this area will require the confluence of disciplines and the collaboration of music librarians, MIR researchers, users, and designers.

\section{Acknowledgements}

The author wishes to thank the anonymous survey participants from CAML for their time. Thank you to Jamshid Beheshti for his guidance throughout the research project and his helpful suggestions on the manuscript. Special thanks to Catherine Guastavino for her assistance with interpreting the results and to Johanna Devaney and Andrew Hankinson for their helpful suggestions on the manuscript. This research was supported by a First-Time Presenter Award for the CAML conference in 2016.

43. See for example, the "Digital Libraries for Musicology" workshops: http://www.transformingmusicology.org/dlfm2017/.

44. Dunn et al., "Variations2: Retrieving and Using Music in an Academic Setting." 


\section{Bibliography}

Bainbridge, David, Michael Dewsnip, and Ian H. Witten. "Searching Digital Music Libraries." In Digital Libraries: People, Knowledge, and Technology. Springer e-book, 2002.

Bainbridge, David, Xiao Hu, and J. Stephen Downie. "A Musical Progression with Greenstone: How Music Content Analysis and Linked Data Is Helping Redefine the Boundaries to a Music Digital Library." In 1st International Workshop on Digital Libraries for Musicology (DLfM '14), 1-8. New York: ACM, 2014.

Barthet, Mathieu, and Simon Dixon. "Ethnographic Observations of Musicologists at the British Library: Implications for Music Information Retrieval." In Proceedings of the 12th International Society for Music Information Retrieval Conference (ISMIR 2011), 353-58. Miami, Florida: ISMIR, 2011.

Baumer, Eric P. S., David Mimno, Shion Guha, Emily Quan, and Geri K. Gay. "Comparing Grounded Theory and Topic Modeling: Extreme Divergence or Unlikely Convergence." Journal of the Association for Information Science and Technology 68, no. 6 (2017): 1397-1410.

Breckbill, Anita. "The Trial of Searching for Musical Works Using Resource Discovery Tools." In Planning and Implementing Resource Discovery Tools in Academic Libraries, edited by M. Pagliero Popp and D. Dallis, 662-76. Hershey, PA: Information Science Reference, 2012.

Carley-Baxter, Lisa R., Craig A. Hill, David J. Roe, Susan E. Twiddy, Rodney K. Baxter, and Jill Ruppenkamp. "Does Response Rate Matter? Journal Editors Use of Survey Quality Measures in Manuscript Publication Decisions." Survey Practice 2, no. 7 (2009): 1-7.

Damm, David, Christian Fremerey, Verena Thomas, Michael Clausen, Frank Kurth, and Meinard Müller. "A Digital Library Framework for Heterogeneous Music Collections: From Document Acquisition to Cross-Modal Interaction." International Journal on Digital Libraries 12, no. 2 (2012): 53-71.

Dougan, Kirstin. "Finding the Right Notes: An Observational Study of Score and Recording Seeking Behaviors of Music Students." The Journal of Academic Librarianship 41, no. 1 (2015): 61-67.

- - . "Information Seeking Behaviors of Music Students." Reference Services Review 40 (2012): 558-73.

- - " "Music Information Seeking Behavior: Then and Now." In Trends in Information Seeking, Behavior, and Retrieval for Creativity, edited by Petros Kostagiolas, Konstantina Martzoukou, and Charilaos Lavranos, 42-57. Hershey, PA: IGI Global, 2016.

Downie, J. Stephen, Donald Byrd, and Tim Crawford. "Ten Years of ISMIR: Reflections on Challenges and Opportunities." In Proceedings of the 10th International Conference on Music Information Retrieval (ISMIR), 13-18. Kobe, Japan: ISMIR, 2009. 
Dunn, Jon W., Donald Byrd, Mark Notess, Jenn Riley, and Ryan Scherle. "Variations2: Retrieving and Using Music in an Academic Setting." Communications of the ACM 49, no. 8 (2006): 53-58.

Glaser, Barney G., and Anselm L. Strauss. The Discovery of Grounded Theory: Strategies for Qualitative Research. New York, NY: Adeline de Gruyter, 1967.

Gobo, Giampietro. Doing Ethnography. London: Sage, 2008.

Hankinson, Andrew, Laurent Pugin, and Ichiro Fujinaga. "Interfaces for Document Representation in Digital Music Libraries." In Proceedings of the 10th International Conference on Music Information Retrieval (ISMIR), 39-44. Kobe, Japan: ISMIR, 2009.

Hume, Margaret. "Searching for Media in the Online Catalog: A Qualitative Study of Users." The Journal of Academic Media Librarianship 3, no. 1 (1995): 1-28.

Inskip, Charles, Richard Butterworth, and Andrew MacFarlane. "A Study of the Information Needs of the Users of a Folk Music Library and the Implications for the Design of a Digital Library System." Information Processing and Management 44, no. 2 (2008): 647-62.

Inskip, Charles, and Frans Wiering. "In Their Own Words: Using Text Analysis to Identify Musicologists Attitudes Towards Technology." In Proceeedings of the 16th International Society for Music Information Retrieval Conference (ISMIR), 455-61. Malaga, Spain, 2015.

King, David M. "Catalog User Search Strategies in Finding Music Materials." Music Reference Services Quarterly 9, no. 4 (2007): 1-25.

Lai, Katie, and Kylie Chan. “Do You Know Your Music Users' Needs? A Library User Survey That Helps Enhance a User-Centered Music Collection." The Journal of Academic Librarianship 36, no. 1 (2010): 63-69.

Laplante, Audrey, and Ichiro Fujinaga. "Digitizing Musical Scores: Challenges and Opportunities for Libraries." In Proceedings of the 3rd International Workshop on Digital Libraries for Musicology (DLfM 2016), 45-48. New York, NY, 2016.

Lee, Jin Ha, Hyerim Cho, and Yea-Seul Kim. "Users' Music Information Needs and Behaviours: Design Implications for Music Information Retrieval Systems." Journal of the Association for Information Science and Technology, 2015, 1-30.

Lee, Jin $\mathrm{Ha}$, and Sally Jo Cunningham. "Towards an Understanding of the History and Impact of User Studies in Music Information Retrieval." Journal of Intelligent Information Systems 41, no. 3 (2013): 499-521.

Lynch, Clifford. "Digital Collections, Digital Libraries and the Digitization of Cultural Heritage Information." First Monday 7, no. 5 (2002).

Pardo, Bryan, Jonah Shifrin, and William Birmingham. "Name That Tune: A Pilot Study in Finding a Melody from a Sung Query." Journal of the American Society for Information Science and Technology 55, no. 4 (2004): 283-300. 
Puckett Sasser, Patricia. "Sounds of Silence: Investigating Institutional Knowledge of the Use and Users of Online Music Collections." Music Reference Services Quarterly 12, no. 3-4 (2009): 93108.

Schedl, Markus, Emilia Gomez, and Julian Urbano. "Music Information Retrieval: Recent Developments and Applications." Foundations and Trends in Information Retrieval 8, no. 2-3 (2014): 127-261.

Shih, Tse-Hua, and Xitao Fan. "Comparing Response Rates from Web and Mail Surveys: A MetaAnalysis." Field Methods 20, no. 3 (2008): 249-71.

Snyder, Tracey. "Music Materials in a Faceted Catalog: Interviews with Faculty and Graduate Students." Music Reference Services Quarterly 13, no. 3/4 (2010): 66-95.

Wang, Avery. "The Shazam Music Recognition Service." Communications of the ACM 49, no. 8 (2006): 44-48.

Witten, Ian H., David Bainbridge, and David M. Nichols. How to Build a Digital Library. Amsterdam: Morgan Kaufmann, 2010. 


\section{Appendix: Survey questions}

\section{Objective}

Our research investigates the current state-of-the-art of digital collections and digital libraries and the extent to which the designs and structures meet the needs of librarians in preserving, collecting, organizing, and disseminating diverse types of music documents and the needs of users in accessing, searching, and retrieving this material.

Thank you for volunteering to participate in this survey. All of the data that we collect will be entirely confidential, viewed only by the research team and shared only as aggregated results. Your confidentiality will be preserved and your name will not be associated with the information you provide.

About you

1. What is your current job title?

2. How many years have you worked in this position?

3. At which library/archives/centre are you currently employed? (optional)

4. Name of Organization/Institution (optional)

About your library

The following questions concern digital collections related to music that your specific library or organization owns and hosts.

5. Does your library host any digital collections?

Yes/No

[If no, survey skips to question 13]

6. What kind of digital collections does your library host? (check all that apply)

- Audio

- Video

O Text

- PDF scores

- Symbolic scores (e.g., MIDI)

O Other (please specify)

7. What kind of access is available for your hosted digital collections? (check all that apply)

- Open access

- Library patrons only

O Other (please specify)

8. How are these digital collections hosted? (check all that apply)

- Individual websites

- Integrated with library catalogue discovery tools

- Housed on another website (e.g., internet archive)

O Other (please specify) 
9. What are the main reasons for hosting the digital collection? (provide ranking, 1=highest priority, 4=lowest priority)

Preservation of materials

- Organization

- Providing access to users

- Research

10. How would you characterize your digital collections? (check all that apply)

- Single type of music representation (e.g., audio only)

- Integration of diverse music representations (e.g., audio, video, and scores) through text-based metadata

- Integration of diverse music representations (e.g., audio, video, and scores) through contentbased access

O Other (please specify)

11. What challenges have you encountered in hosting digital collections? (provide ranking, $1=$ biggest challenge, $7=$ smallest challenge)

- Budgetary

- Technology (hardware)

- Technology (software)

- Functionality issues

- Interface design

- Staff support

- Copyright

12. Please elaborate on any challenges you encountered hosting digital collections. [After completing question 12, the participants skip to question 15]

13. If your library does not host any digital collections, what are the major barriers preventing your library from doing so? (provide ranking, $1=$ biggest barrier, $6=$ smallest barrier)

- Budgetary

- Technology (hardware)

- Technology (software)

- Functionality issues

- Interface design

- Staff support

- Copyright

14. If needed, please elaborate on any barriers preventing you from hosting digital collections.

About your patrons

These questions are based on your experiences with and knowledge of your patrons or users.

15. To what extent are your library patrons aware of the digital collections that your library hosts?

o Intimately aware

○ Very aware 
- Somewhat aware

- Not very aware

- Completely unaware

○ N/A

16. To what extent are your patrons aware of digital collections or digital libraries that are open access or that your library subscribes to?

- Intimately aware

- Very aware

- Somewhat aware

- Not very aware

- Completely unaware

- I don't know

17. How satisfied are your patrons with available digital collections or digital libraries?

○ Very satisfied

- Satisfied

- Neutral

- Unsatisfied

- Very unsatisfied

o I don't know

18. How important are digital collections or digital libraries to your patrons for research?

- Extremely important

- Very important

○ Somewhat important

- Not important

- Not at all important

- I don't know

19. What types of functionalities for information-seeking are important for your patrons? (select all that apply)

○ Browsing

- Quick search

- Advanced search

- Faceted navigation

O Other (please specify)

20. Do your patrons report any issues with access or functionality with digital collections or digital libraries? If so, what type of issues?

21. Other comments about your patrons' use of digital collections

About digital libraries in general and future designs

Have you been involved with designing digital collections or digital libraries? (check all that apply)

$\circ$ Lead designer

- Intimately involved 
- Involved

- Limited involvement

- Not involved

O Other (please specify)

22. Would you be interested in participating in the design of digital libraries in the future?

$\circ$ Very interested

○ Interested

- Neutral

- Uninterested

o Very uninterested

23. To what extent would the following Music Information Retrieval (MIR) techniques and linked data technologies be beneficial to incorporate into digital libraries?

\begin{tabular}{|l|l|l|l|l|l|}
\hline & $\begin{array}{l}\text { Very } \\
\text { beneficial }\end{array}$ & Beneficial & Neutral & $\begin{array}{l}\text { Not } \\
\text { beneficial }\end{array}$ & $\begin{array}{l}\text { Not at all } \\
\text { beneficial }\end{array}$ \\
\hline Serendipitous discovery processes & & & & & \\
\hline Visualizations of search results and data & & & & & \\
\hline Search by audio snippet & & & & & \\
\hline Query-by-humming & & & & & \\
\hline Search by similarity (content-based approach) & & & & & \\
\hline $\begin{array}{l}\text { Relationships between genres, artists, works, topics } \\
\text { shown through semantic links }\end{array}$ & & & & & \\
\hline Collaborative social features (e.g., playlist creation) & & & & & \\
\hline $\begin{array}{l}\text { Multi-modal interface integration and alignment } \\
\text { (e.g., sound recording and score) }\end{array}$ & & & & & \\
\hline
\end{tabular}

24. How could the access or functionality to digital collections or digital libraries be improved?

25. What do you see as the future of digital music libraries?

26. Do you have any other comments related to your experiences with digital collections or digital libraries?

27. In addition to this survey, we would like to invite you to participate in a short telephone/Skype interview to discuss your experiences in more detail. Would you be interested in volunteering in a telephone/Skype interview?

YES/NO

E-mail Address:

Thank you for your participation in this survey. 